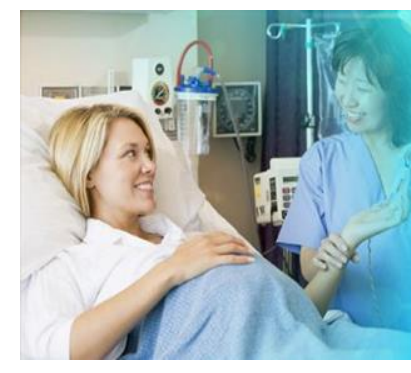

E-ISSN: 2664-2301 P-ISSN: 2664-2298 IJOGN 2022; 4(1): 01-04

Received: 17-10-2021 Accepted: 02-12-2021

\section{Arkierupaia Shadap} Associate Professor, Sikkim Manipal College of Nursing, Sikkim Manipal University, Sikkim, India
Corresponding Author: Arkierupaia Shadap Associate Professor, Sikkim Manipal College of Nursing, Sikkim Manipal University, Sikkim, India

\section{Evidence based practice in midwifery care}

\author{
Arkierupaia Shadap
}

DOI: https://doi.org/10.33545/26642298.2022.v4.i1a.75

\begin{abstract}
Midwifery in India has climbed up the ladder of progression from before independence till the present day. Midwifery care introduces a system level shift from fragmented maternal and newborn care focused on identification and treatment of pathology, to skilled and compassionate woman-centric care. The maternity care gives priority to effective care with least harm. Evidence-based practice (EBP) is a conscientious, explicit and judicious use of the current best evidence in making decisions regarding the individual patients' care. Evidence based midwifery are care that ensure the practices in the midwifery settings based on clear and acceptable evidence that supports their clinical practice. PICOT questions play a significant role in guiding evidence-based practice since they guide in conducting profound research in practice. EBP uses well-defined criteria to evaluate the quality of clinical research, creating a hierarchy of evidence. It has become a global phenomenon, and is at the forefront of practice. Indeed, it is the linchpin to contemporary woman-centered maternity care in the present era.
\end{abstract}

Keywords: Evidence based practice (EBP), midwives, midwifery care, PICOT, hierarchy

\section{Introduction}

Brief historical review of midwifery: Midwifery is as old as the history of human species. Archeological evidence of woman demonstrates the existence of midwifery in $5000 \mathrm{BC}$. It is also seen in the Old Testament. The King of Egypt spokes to the midwives, who helped Hebrew women when they gave birth and they were the first found in the literature. Hippocrates (460BC) also organized trained and supervised Midwives. The history of midwives was also seen during the time of Aristotle (384-322BC) where he described the essential qualities of the midwife.

\section{Development of maternity services}

Globally

- Following reformation in 16th century the Church of England issue the License of midwives to practice.

- In 1756 Dr. John Douglas recommended that proper instructions to be given to the midwives.

- In 1902, the first English midwives' act was passed and state registration of midwives became mandatory by law.

- From 1700 to 1900 , the time of rapid development.

In India

- Maternal and child health services in India were started with the help of voluntary organizations.

- Modern maternal and child health work was begun in India by foreign missionaries with an effort to train dais.

- The time line are as follows:

- 1918 - Lady Reading Health School was started in Delhi (LHV)

- 1921 - Lady Chelmsford was formed in India for developing maternity and child welfare services.

- 1931 - Indian Red Cross society established MCH Bureau in association with the Lady Chelmsford League

- Madras $-1^{\text {st }}$ State then to set up a separate section for maternal and child welfare in the public health department.

- In 1926- Madras Registration of Nurses and Midwifes Act was passed to promote the role of a registered midwife. 
- In 1946 - Bhore Committee laid stress on the need for qualified midwives, health visitors, and the training of dais.

- In 1947- the first step the INC took after its inception to combine the nursing and the midwifery courses.

Midwifery in India has climbed up the ladder of progression from before independence till the present day. Indian Public heath system also experienced a rapid expansion of health care delivery infrastructure and phenomenal growth in the number of institutional deliveries. However, this impressive increase has not led to an expected commensurate decline in maternal and neonatal mortality. Nearly 32, 000 pregnant women each year still lose their lives during pregnancy, childbirth and postnatal period.

\section{In addition}

Table 1: Neonatal mortality rate

\begin{tabular}{|c|c|}
\hline Newborn die each year & $5,90,000$ in the first month of life \\
\hline Neonatal mortality rate & 24 per 1000 live births \\
\hline $\begin{array}{c}\text { Early neonatal mortality } \\
\text { rate }\end{array}$ & $\begin{array}{c}18 \text { per } 1000 \text { live births (serious cause of } \\
\text { concern) }\end{array}$ \\
\hline
\end{tabular}

The disparities in distribution of these deaths are based on socio-demographic variables. Efforts are needed in India to increase Universal Health Coverage and to achieve the SDGs for maternal, newborn and child health. One of the major contributors towards maternal deaths is poor quality of intra partum care. As per Lancet Newborn' series of 2014, the time of labour and childbirth accounts for almost $46 \%$ of maternal deaths and $40 \%$ of stillbirths and neonatal deaths. The two major reasons for poor intra-partum care are lack of trained service providers and over medicalization of the delivery process. This suggests the need for improving quality of care (midwives) during intra-partum period in public and private healthcare institutions.

According to a study published in The Cochrane Library, maternity care that involves a midwife as the main care provider leads to several positive outcomes with no adverse effects for both mothers and their babies. In several countries, midwives represent the main providers of care for women during pregnancy, labour and birth. Researchers from King's College London, Sheffield Hallam University, the University of Warwick and the National University of Ireland Galway analyzed data from 13 studies involving a total of 16,242 women. The study findings showed that when midwives were the main providers of care during pregnancy, women were less likely to give birth prematurely or lose their babies before 24 weeks of gestation. It also revealed that pregnant women were reported to be happier with the care they received, had fewer epidurals, fewer assisted births, and fewer episiotomies to reduce the risk of a tear.

\section{What is Midwifery?}

Skilled, knowledgeable and compassionate care for childbearing women, new-born infants and families across the continuum throughout pre-pregnancy, pregnancy, birth, postpartum and early weeks of life.

\section{Who is a Midwife?}

Midwives provide care for women throughout the pregnancy and childbirth and are the lead health professional for those women whose pregnancies are uncomplicated. Midwives work as part of a team of healthcare professionals including health visitors and social workers.

\section{Role of Midwife}

The midwife's role is very diverse. Their work includes:

1. Carrying out clinical care

2. Supporting the mother and her family throughout the childbearing process

3. Providing health education - antenatal, postnatal

4. Preparation for parenthood and extends to certain areas of gynecology, family planning and childcare.

\section{Skills required being a midwife}

1. An understanding and caring attitude

2. An ability to get on well with people

3. Emotional and mental strength

4. Good observer

5. An ability to act on own initiative

6. Patience

7. Maturity

8. Willingness to take responsibility

8. Ability to cope with distressing situations and to remain calm

9. Counselor, good listener and with good general communication skills

10. Be aware of the social and cultural context in which childbirth takes place.

\section{Evidence-based practice}

Evidence-based practice is a conscientious, explicit and judicious use of the current best evidence in making decisions regarding the individual patients' care.

\section{What is evidence- based midwifery?}

Evidence based midwifery are care that ensure the practices in the midwifery settings based on clear and acceptable evidence that supports their clinical practice.

\section{Importance of EBP in maternity care}

Evidence-based is the linchpin to contemporary womancentered maternity care. The maternity care gives priority to effective care with least harm. A rigorous, well-conducted systematic review of original studies yields the most reliable knowledge about beneficial and harmful effects of specific interventions. Quality published research is now a necessary and frequently accessed source of midwifery knowledge. This means that midwives need to be involved in carrying out research and know how to make use of research in their clinical practice. These two themes covering the production and use of research lie within the context of evidence-based maternity services. Midwifery care introduces a system level shift from fragmented maternal and newborn care focused on identification and treatment of pathology, to skilled and compassionate woman -centric care.

\section{Steps of Evidence based Practice \\ 1. Develop a clinical question \\ 2. Search for the best available evidence \\ 3. Appraise the evidence \\ 4. Apply the best available evidence \\ 5. Evaluate the outcomes}

Formulating a Questions

Use a PICOT framework to write a question to guide your 
search for evidence. PICOT questions play a significant role in guiding evidence-based practice since they guide in conducting profound research in practice.

\section{Developing Clinical Questions}

$\begin{array}{lc}\text { The PICOT Format } & \text { Types of Clinical Questions } \\ \text { P - Patient or Problem } & \text { Diagnosis } \\ \text { I - Intervention } & \text { Prognosis } \\ \text { C - Comparison } & \text { Therapy } \\ \text { O - Outcome } & \text { Harm } \\ \text { T - Time } & \text { Prevention }\end{array}$

\section{Example of a formulated PICOT Questions}

Pregnant woman at 7 months gestational age complaints of having severe legs cramps by the end of the day. Is taking extra calcium will likely help reducing leg cramps? Will there be any side effect from the extra calcium intake?

\author{
The question can be broken down into PICOT: \\ P- Participants -Pregnancy woman \\ I- Intervention - Extra calcium intake \\ C- Comparison - Compared with pregnant woman on \\ routine exercise \\ O- Outcome - Reduction of leg cramps \\ T- Timeframe - During pregnancy
}

\section{Types of evidence}

EBP uses well-defined criteria to evaluate the quality of clinical research, creating a hierarchy of evidence.

1. a) Systemic reviews of RCTs

b) Individual RCTs

2. a) Systematic reviews of cohort studies

b) Individual cohort studies and low-quality RCTs

3. a) Systematic reviews of case-control studies

b) Case-controlled studies

4. Case series poor-quality cohort and case-control studies

5. Expert opinion

\section{The rise of evidence-based practice in health care}

Revolutionized the service delivery in the healthcare system. Within an incredibly short time period, EBP has become a global phenomenon, and is at the forefront of practice. It was first introduced as a way of encouraging doctors to make use of the increasing amount of knowledge available through medical research to improve the standard of medical care. The evidence-based movement spread rapidly from medicine to other health care groups including midwifery as an essential method of clinical decision-making. It was designed to replace tradition, intuition, or person preferences as the basis for decisions on patient investigations and treatments. The emphasis was on the 'science' of medicine rather than the 'art' of medicine. Midwives have a crucial role in providing optimal care for pregnant women. One of the most important policies for quality improvement in maternity care is implementation of evidence-based practice. However, the application of evidence-based practice within the maternity health care setting faces many challenges.

\section{Challenges faced \\ 1. Limitations of time \\ 2. Heavy workload \\ 3. Inadequate facilities \\ 4. Negative attitudes}

5. Lack of cooperation of physicians.

6. Feeling of inadequate authority. The midwife does not feel they have enough authority to change patient care procedures.

7. High qualities studies for evidence not available

8. Inadequate knowledge and skills in EBP.

\section{Benefits of EBP for midwives}

1. Increased job satisfaction

2. Empowerment

3. Improved skills to integrate patient preferences into practice

4. Support for professional growth

5. Continuous career development through expert roles.

\section{Conclusion}

To enhance the implementation of EBP, strategies should be placed to minimize barriers such as providing adequate material and human resources, familiarity with organizations with the best sources of evidence/Cochrane and managerial support for increasing professional legitimate authority. It is important that nurses and midwives make a commitment to EBP and update their clinical competence by regularly following professional sources of evidence in the field. We need to develop the necessary skills required to access the best available evidence and use evidence appropriately in our practice.

\section{Funding: None}

\section{Conflict of interest: None}

\section{References}

1. Sackett DL, Rosenberg WMC, Gray JAM, Haynes RB, Richardson WS. Evidence based medicine. What it is and what isn't. BMJ. 116;312:721-2.

2. Ministry of Health and Family Welfare Government of India. Guidelines on Midwifery Services. India. 2018.

3. Brown CE, Wickline MA, Ecoff L, Glaser D. Nursing practice, knowledge, attitudes and perceived barriers to evidence-based practice at an academic medical center. J Adv Nurs. 2009;65(2):371-381. https://doi.org/10.1111/ j.1365-2648.2008.04878.x

4. Breimaier HE, Halfens RJ, Lohrmann C. Nurses ' wishes, knowledge, attitudes and perceived barriers on implementing research findings into practice among graduate nurses in Austria. J Clin Nurs. 2011;20(1112):1744-1756. https://doi.org/10.1111/j.1365-2702.2010.03491.x

5. Khammarnia M, Haj Mohammadi M, Amani Z, Rezaeian S, Setoodehzadeh F. Barriers to implementation of evidence based practice in zahedan teaching hospitals, Iran, 2014. Nurs Res Pract. 2015;2015:1-5. https://doi.org/10.1155/2015/357140.

6. Yazdizadeh B, Nedjat S, Mohammad K, Rashidian A, Changizi N, Majdzadeh R. Cesarean section rate in Iran, multidimensional approaches for behavioral change of providers: a qualitative study. BMC Health Serv Res. 2011;11:159. https://doi.org/10.1186/1472-6963-11159.

7. Kajermo KN, Boström A-M, Thompson DS, Hutchinson AM, Estabrooks CA, Wallin L. The BARRIERS scalethe barriers to research utilization scale: a systematic review. Implement Sci. 2010;32(5):1-22. https://doi. 
org/10.1186/1748-5908-5-32.

8. Schuman A, Marteau T. Obstetricians' and midwives' contrasting perceptions of pregnancy. J Reprod Infant Psychol. 1993;11:115-118.

https://doi.org/10.1080/02646839308403203

9. Azmoude E, Aradmehr M, Dehghani F. Midwives' attitude and barriers of evidence based practice in maternity care. Malays J Med Sci. 2018;25(3):120-128. https://doi.org/10.21315/mjms2018.25.3.12

10. Pearson A, Wiechula R, Court A, Lockwood C. The JBI model of evidence-based healthcare. Int $\mathrm{J}$ Evid Based Healthc. 2005;3(8):207-15.

11. Sackett DL, Richardson WS, Rosenberg W, Haynes B. Evidence-based medicine: how to practice and teach EBM. Edinburgh: Churchill Livingstone. 1997.

12. Newhouse RP, Spring B. Interdisciplinary evidencebased practice: moving from silos to synergy. Nurs Outlook. 2010;58(6):309-17.

DOI: 10.1016/j.outlook.2010.09.001. 